\title{
Adopting open innovation strategy to empower SMEs in developing countries
}

\author{
Gebremichael S. Hailekiros ${ }^{1, a}$, Hou Renyong ${ }^{1}$, Sun Qian ${ }^{1}$ \\ ${ }^{1}$ School of Management, Wuhan University of Technology, Wuhan, P.R. of China, 430070
}

Key words: Open innovation, Adoption, Collaboration, SMEs, Developing countries

\begin{abstract}
Recently open innovation practice in SMEs has received an extensive attention in the scientific research, management and government. Nonetheless, most previous studies were contextualized to firm's capabilities and quality of the external knowledge infrastructures from the advanced countries. Studies on the practices of open innovation in SMEs from developing countries are scant. Researching the practice and benefit of OI strategy with regard to the actual capabilities of SMEs and the actual technological and knowledge infrastructures is imperative. This paper explores how open innovation strategy could be adopted to accelerate the technological learning and performance of SMEs in developing countries. It examined the practices and trends and searched contextual framework for adopting open innovation practice of SMEs in developing countries. The paper shows that establishing synergetic relationship oriented towards the jointly and individually creation, diffusion and usage of knowledge is critical to boost the SMEs' learning capability and performance in developing countries.
\end{abstract}

\section{Introduction}

Open innovation (OI) is projected to be one of the emerging future paradigm for innovation management $[1,2]$. It is defined as "the use of purposive inflows and outflows of knowledge to speed up the internal innovation, and to increase the markets for external use of the innovation respectively" [3]. It describes both internal and external ideas and paths as equally important for commercializing innovations $[1,2]$. Recently the subject has received an increasing attention in research, management and government, yet most previous works that based on in-depth interviews and cases studies were dominated by the practice of large and high-tech multinational enterprises $[1,4,2]$. Thus, the OI literature is shallow on small and medium-size enterprises (SMEs) [5]. Fewer studies described the practice of OI in SMEs $[4,5]$. Besides, these studies were contextualized to the firm's capabilities and external knowledge infrastructures from the advanced countries [1, 6, 7, 8, 4]. The OI practice both in large and SMEs in developing countries is not yet investigated. Obviously, encouraging innovation in SMEs is central to policy initiatives for stimulating economic development at the local, regional, and national levels in developing countries [9]. They are increasingly playing important role in innovation,

a Corresponding author : hailishs@yahoo.com 
but often lack resources to develop and commercialize new products in-house and are more prone to collaboration and openings [4]. They must collaborate with external partners to innovate successfully, develop new sources of income, and reach more profitable positions in the competitive landscapes [10]. Moreover, as the innovation becomes so complex and difficult to be handled by one firm and the pertinent knowledge is distributed across various firms and institutions [3, 4], the governments and relevant bodies need to take the assignment to integrate SMEs towards the development initiatives. The important issues is then how to adopt the OI strategy to accelerate the technological learning and performance of SMEs in developing countries. This question is important for policy makers to make the SMEs competitive and tune their activities towards the growth strategies. It is necessary then future researches explicitly analyze the practice and benefit of OI strategy with regard to the actual capabilities of SMEs and the technological and knowledge infrastructures of these countries. This paper explores the above issue and examines the practices, trends and the theoretical implications of open innovation of SMEs in developing countries.

\section{Research methodology}

This paper is a theoretical research paper. It builds on literature reviews covering various dimensions of OI and its applicability to SMEs in developing countries. It also describes the networks and mechanisms of its adoption to suit the economic, capability and infrastructural facilities. The articles for this study were collected from Science direct, emerald insight and google scholar databases using combination of "open innovation", "developing countries" and "SMEs" as keywords. After careful reading of the abstract, conclusion and the main body (when required), the pertinent papers were selected to build the empirical evidences and the frameworks.

\section{Literature review \\ 3.1. Open innovation in SMEs}

Traditionally firms used the R\&D facilities to discover, develop and commercialize technologies in a closed model [1].But the globalization and fast advancing information technology [11] have changed the innovation milieu. The increasing availability and mobility of knowledgeable workers, abundant venture capital and widely dispersed knowledge across multiple organizations, enterprises are moving to an OI model to efficiently use both internal and external sources to exploit technologies and acquire knowledge [1]. The SMEs are not immune or unconscious to this development, OI is similarly a common inclination by SMEs $[8,4]$. Many SMEs try to survive the severe competition and achieve their sustainable competitive advantages through innovation. Nonetheless, high level inherent risk, complexity, and uncertainty of innovation process [12], limited resources [2, 13, 14], lack of multidisciplinary competence base [15], low absorbing capacity [11] and other relevant challenges may restrict their innovative competitiveness. Moreover, in a world of mobile workers, abundant venture capital, widely distributed knowledge and reduced product life cycles, it is not feasible for most enterprises to innovate on their own [1]. Hence, many and broad companies both large and small are practicing and increasingly adopting OI to complement their inadequacies $[4,16]$.

Indeed, SMEs have limited resources and capabilities in manufacturing, distribution, and marketing, R\&D funding and structural innovation processes which are indispensable for transforming inventions into products or processes $[8,17]$. However, they are usually flexible and specific [2], less bureaucratic, more risk takers, with more specialized knowledge, and proactive for market demand changes [16]. These factors favor SMEs to better benefit from the OI activities compared with their larger counterparts [18].In this regard, SMEs can use the in-bound, out-bound and coupled OI processes $[19,5]$ as paths towards the opening strategy. While the in-bound referees searching for external information to complement, strengthen or speed up the in-house R\&D activities; the outbound process uncovers the way for commercializing unused internal innovation activities. The coupled process combines both in- and-out-bound processes centered on strategic alliances [5]. These processes are important for SMEs to fill their technological, resource and competence gaps [8], 
increase the speed and quality of innovations [4], react to market changes and develop new channels $[4,2]$.

\subsection{In-bound open innovation}

In the OI era firms heavily depend on the proper search and combined utilization of both internal and external information sources [5]. Customers, suppliers, competitors, universities, public research organizations, consultants, professional and industrial associations, among others are some of the key external sources for useful information [17]. As the SMEs have relatively limited resources to internally develop valuable information, the use of external expertise is an important means to improve and speed up their innovation processes $[4,5]$. Inbound OI is thus a strategic choice for the SMEs [8]. Under this circumstance, they can use customer involvement, external networking, external participation, outsourcing R\&D and inward licensing of IP to gain access to the external knowledge.

OI theorists recognize that customer involvement is one important alternative to inform internal innovation processes [20]. Users are increasingly becoming innovation developers by modifying current machines, equipment and software's to fit with the actual process needs or inadequate supplies [21]. Hence, firms can benefit from their customers' ideas and innovations by proactively researching the market, providing tools to experiment with and/or develop products similar to the products, or by producing products based on the designs of customers [4]. Similarly, the external networking, the formal or informal connections with external environment [6], allows enterprises gain specific knowledge at lower cost and shorter time than developing or acquiring internally [4]. Likewise external participations enable the recovery of innovations that were initially abandoned or that did not seem promising [22]. Under the assumption of open paradigm enterprises cannot conduct all R\&D activities by themselves, rather they have to capitalize on external knowledge which can be licensed or bought $[20,4]$. Likewise, they may outsource $R \& D$ activities to acquire external knowledge from engineering and research institutions [4]. They can also externally acquire machinery, equipment, software and other external knowledge sources [5] key for speeding up and nurturing the internal research practices [4] and benefiting from the external innovation activities [22].

\subsection{Out-bound open innovation}

The out-bound is the external paths to commercialize internal innovations that are not used by the innovating company [5]. It includes venturing, outward licensing of intellectual property (IP), and linking non-R\&D workers to innovation initiatives $[1,4]$. Venturing is the process of starting up new organizations based on internal knowledge and support of parent organization. It is a spin-off process and is considered as an enormous potential for increasing the market values of innovation activities [1]. The out ward licensing of IP plays an important role as a result of the in- and-outflows of knowledge [1]. When the IP has a profitable external path to market through other firms, the IP owner enterprise will have an opportunity to generate revenues in the form of licensing payments [4], gain competitive advantage through a standard setting based on internally developed technology [23] and generate insights into new markets [8]. Moreover, as innovation has become more knowledge-based and less rigidly defined, using the initiatives and knowledge of current employees outside the R\&D department is one means to benefit from the internal knowledge for commercializing innovations [6].

\subsection{Coupled open innovation}

The coupled process combines both innovations focused on research cooperation's [4]. It is believed to have advantages in improving capabilities in absorbing external knowledge and accessing the intangible tacit knowledge and knowhow residing in the innovation partners [5]. It also reduces the outgoing spillovers by internalizing among few alliance partners [4], allowing research partners for 
the exploitation of economies of scale and scope in R\&D and reducing innovation costs [4]. The SMEs characterized by lack of technological assets, expertize and limited resources, have strong incentive to search partners to supplement these limitations and enhance their performances [2]. Thus, innovation oriented networks could bring the opportunities to generate economies of scale, ensure the provision of support services, reduce risk, increase operational flexibility and market shares for their products [2]. SMEs are endowed with superior ability to use external networks better than large firms $[24,16]$.

\section{Open innovation business model for SMEs in developing countries}

Constrained with limited resources and capabilities, SMEs must find ways to minimize production cost, effectively market their products and provide satisfactory support services [2].They have to formally or informally tie with other organizations and institutions [25]. These connections (错误!未 找到引用源。) are critical for them to access new ideas, knowledge, complementarity resources, and opportunities to commercialize on the shelf innovations and gain legitimacy from external environment [13].

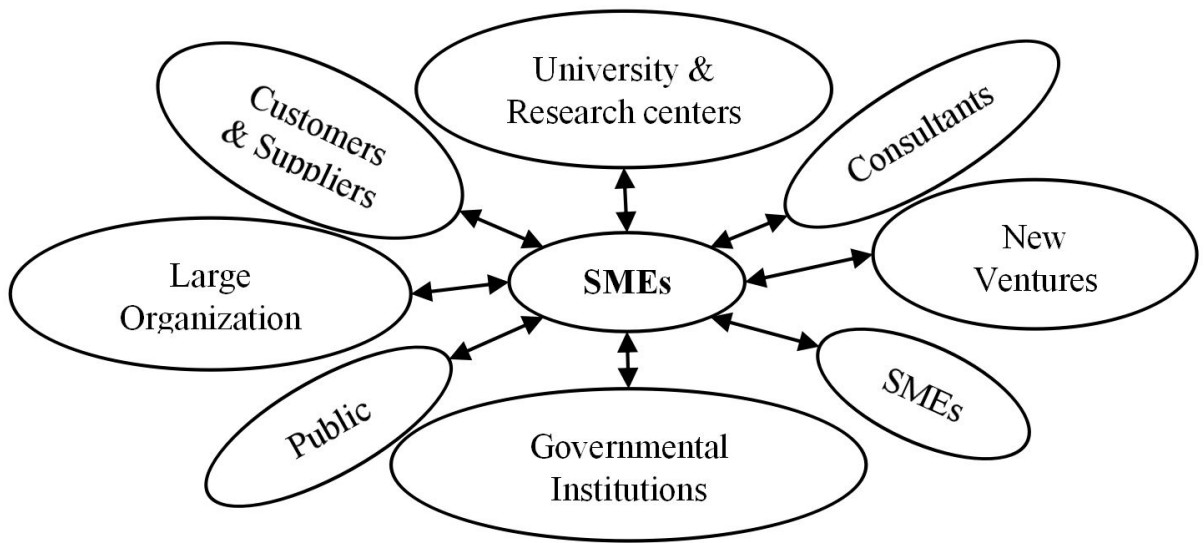

Figure 1. Collaborations and interactions of SMEs with the external environment

Although the developing countries are thought to have poor industrial, export and innovation capabilities and be mainly imitators or adopters of technologies and knowledge developed elsewhere, the trend is changing [10]. Currently, many developing countries are advancing their infrastructures, capabilities and commercializing many innovations [11]. SMEs are becoming key sources of the innovation and sustainable growth in many economies in this group [26]. In addition they are familiarizing their entrepreneurships through university spin-offs and intensifying the industryuniversity relations to commercialize ready-made knowledges [10]. In this context (错误!未找到引用 源。), while the governments play strong role in creating the network [27], financing and steering of institutions and providing financial and regulatory inducements [28], the other stakeholders nurture knowledge of new technologies, market channels, process improvements etc. to the SMEs [29]. Within this relationships, SMEs could form weak or strong ties based on their orientation and focus of innovation [30]. Whereas the Weak ties imply low commitment to alliances and team up of nonfamiliar partners, the strong ties are characterized by intimate, recurrent, and trustful relationships. Furthermore the ties are better fit with the exploration and exploitation innovation strategies respectively [25]. Research findings also showed that medium-sized firms are relatively more involved in OI and have strong ties [4]. Taking the background in to considerations, we argue that the open innovation alternative model developed by [31] can be fitted to describe the SMEs innovation openings in terms of extent of collaboration, locus of innovation and their sizes (Figure 2).

According to this model the opening and collaboration increases as it extends from left bottom corner to the top right corner [25]. Thus the open innovation strategy could be adopted to fit the size, 
capacity and resource requirement of SMEs. The micro and small enterprises with relatively low capacity and limited resources are oriented to have connections and openings at low expenses and supportive in nature. As the capacity, resource and size are relatively increased, multiple participants and more formal and strong ties can be formed.

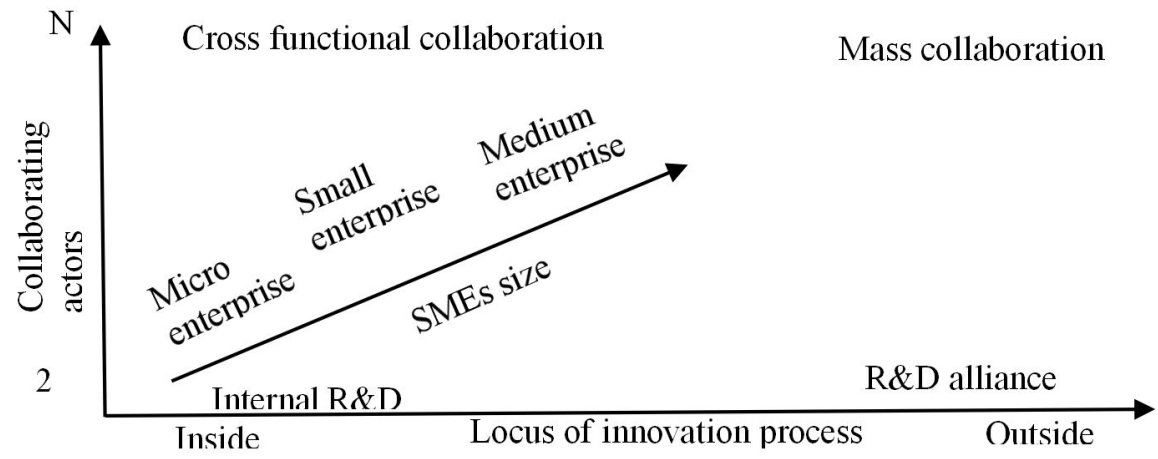

Figure 2. Open Innovation model for SMEs adapted from [31]

\section{Conclusion}

Innovation is the outcome of multifaceted interactions among individuals, firms, industries and other knowledge institutions. Obviously, companies have uniqueness in their internal organization, operational dynamics and ways of action, the open innovation approach cannot be same for every firm and industry. Thus it should be carried out carefully and suited to the different settings of the company in particular and industry in general. Firms in developing countries should modify and adopt the open innovation system to their capability, knowledge and resource infrastructures. With the advancement of new technologies, firms at different locations are capable to use new and low cost collaborations and coordination's. Establishing a synergetic relationships oriented towards the jointly and individually creation, diffusion and usage of knowledge is critical to boost the SMEs' learning capability and performance in developing countries. Accordingly, governments should take the initiatives to establish the network and support the actors with the required infrastructures and policies so as to improve the competitiveness of the SMEs and upsurge their contribution to the economic growth of the countries. Finally, further studies based on primary data are important on this direction to get practical knowledge about the OI adoption strategy, practice and its relevance for SMEs in developing countries.

\section{References}

1. H. W. Chesbrough: Open innovation: The new imperative for creating and profiting from technology. Boston: Harvard Business School Press (2003).

2. S. Lee, G. Park, B. Yoon and J. Park: Open innovation in SMEs - an intermediated network model. Research Policy, vol. 39(2010), p. 290-300.

3. H. Chesbrough, W. Vanhaverbeke and J. West: OI: Researching a New Paradigm. London: Oxford University Press (2006).

4. V. Van de Vrande, J. P. De Jong, W. Vanhaverbeke and M. De Rochemont: Open innovation in SMEs: Trends, motives and management challenges. Technovation. vol. 29(2009), p. 423-437.

5. A. Spithoven, W. Vanhaverbeke and N. Roijakkers: Open innovation practices in SMEs and large enterprises. Small Bus Econ, vol. 41(2013), p. 537-562. 
6. H. Chesbrough and A. K. Crowther: Beyond high tech: early adopters of open innovation in other industries. R\&D Management. vol. 36, no. 3(2006), p. 229-236.

7. X. Lecoq and B. Demil: Strategizing industry structure: the case of open systems in low-tech industry. Strategic Management Journal, vol. 27(2006), p. 891-898.

8. U. Lichtenthaler: Open innovation in practice: an analysis of strategic approaches to technology transactions. IEEE Transactions on Engineering Management, vol. 55, no. 1(2008), p. 148-157.

9. O. Jones and F. Tilley: Competitive Advantage in SMEs: organizing for Innovation and Change. Chichester: Wiley (2003).

10. H. Rahman and I. Ramos: SMEs and OI: Applications and Investigations, USA: IGI Global (2012).

11. Y. Wang and Z. Zhou: Can open innovation approach be applied by latecomer firms in emerging countries? Journal of Knowledge-based Innovation in China, vol. 4, no. 3(2012), pp. 163-173.

12. X. Koufteros, M. Vonderembse and J. Jayaram: Internal and External Integration for Product development. Decision Science, vol. 36, no.1 (2005), p. 97-133.

13. L. Dahlandera and D. M. Gann: How open is innovation? Research Policy, vol. 39, no. 6(2010), p. 699-709.

14. A. Hausman: Innovativeness among small businesses: Theory and propositions for future research. Industrial Marketing Management, vol. 34, no. 8(2005), p. 773-782.

15. M. Bianchi, S. Campodall'Orto, F. Frattini and P. Vercesi: Enabling OI in SMEs: how to find alternative applications for your technologies. R \& D Mgt. vol. 40, no. 4(2010), p. 414-430.

16. V. Parida, M. Westerberg and J. Frishammar: Inbound OI Activities in High-Tech SMEs: The Impact on Innovation Performance. JSBM. vol. 50, no. 2(2012), pp. 283-309.

17. A. Leiponen and C. E. Helfat: Innovation objectives, knowledge sources, and the benefits of breadth. Strategic Management Journal. vol. 31, no. 2(2010), p. 224-236.

18. W. Stam and T. Elfring: Entrepreneurial Orientation and New Venture Performance: The Moderating Role of Intra- and Extra industry Social Capital. AMJ, vol. 51, no. 1(2008), p. 97-111.

19. O. Gassmann, E. Enkel and H. Chesbrough: The future of OI. R\&D Mgt, vol. 40(2010), p. 21321.

20. O. Gassmann: Opening up the innovation process: Towards an agenda. R\&D Management. vol. 36, no. 3(2006), p. 223-228.

21. E. V. Hippel: Democratizing Innovation. MA: MIT Press Cambridge (2005).

22. H. Chesbrough: Open Business Models: How to Thrive in a New Innovation Landscape. Boston, MA: Harvard Business School Press (2006).

23. S. Nagaoka and H. U. Kwon: The incidence of cross licensing: A theory and new evidence on the firm and contract level determinants. Research Policy.vol. 35, no. 9 (2006), p. 1347-1361.

24. V. Van de Vrande, C. Lemmens and W. Vanhaverbeke: Choosing governance modes for external technology sourcing," R\&D Management, vol. 36(2006), p. 347-363.

25. B. Bigliardi, A. I. Dormio and F. Galati: The adoption of OI within the telecommunication industry. European Journal of Innovation Management. vol. 15, no. 1(2012), p. 27 - 54.

26. A. Warner: SMEs and economic creativity. The Role of Finance, Including E-finance, to Enhance Enterprise Development, Geneva 2(2001).

27. I. Savitskaya: Towards open innovation in regional innovation system: Case St. Petersburg. Research Report 214, Lappeenranta: Lappeenranta University of Technology (2009).

28. E. G. Carayannisa, D. Popescu, C. Sipp and M. Stewartd: Technological learning for entrepreneurial development: Technovation. vol. 26, no. 4(2006), p. 419-443.

29. T. Buganza and R. Verganti: Open innovation process to inbound knowledge Collaboration with universities in four leading firms. EJIM. vol. 12, no. 3(2009), p. 306-325.

30. K. Dittrich and G. Duysters: Networking as a means to strategy change: the case of open innovation in mobile telephony. Journal of Product Innovation Management. vol. 24, no. 6(2007), pp. 510-21.

31. M. Elmquist, T. Fredberg and S. Ollila: Exploring the field of open innovation. European Journal of Innovation Management, vol. 12, no. 3(2009), p. 326 - 345. 
32. L. Dahlander and D. M. Gann: How open is innovation? JRP. vol. 39, no. 6(2010), p. 699-709.

33. L. F. Mesquita and S. G. Lazzarini: Horizontal and vertical relationships in developing economies: Implications for SMEs' access to global markets. A. Mgt Journal. vol. 51, no. 2(2008), p. 359-38.

34. T. Edwards, R. Delbridge and M. Munday: Understanding innovation in SMEs: a process manifest. Technovation. vol. 25(2005), p. 1119-1120.

35. A. Fosfuri: The licensing dilemma: Understanding the determinants of the rate of technology licensing. Strategic Management Journal, vol. 27, no. 12(2006), p. 1141-1158.

36. W. Vanhaverbeke, G. Duysters and N. Noorderhaven: External technology sourcing through alliances or acquisitions: Organization Science, vol. 13, no. 6(2002), p. 714-733.

37. B. Bigliardi, F. Galati and G. Petroni: Collaborative modes of R\&D: the new challenges for personnel management. IJBMSS. vol. 2, no. 3(2011), p. 66-74. 